\title{
Prima La Musica, Dopo Le Parole? A Small Note on a Big Topic
}

\author{
Josef Bayer
}

\section{Introduction}

For a linguistic contribution, the choice of my title needs an explanation. The question prima la musica, dopo le parole? ("the music first, the words later?") plays the central role in Richard Strauss' (1864-1949) last opera, Capriccio, first performed in 1942. The work is superficially about a love triangle in which a poet (Prima le parole - dopo la musica! "First the words, the music after!") and a musician ("Prima la musica- $e$ - dopo le parole!" "First the music, the words after!") compete for the love of a countess, but in its heart, it is an extensive dialogue about the relation of form (metaphorically musica) and meaning (metaphorically le parole). I selected it for a start not only because I deeply adore Strauss but also because it may build a bridge to an important issue of contemporary linguistic theory and in particular the relation between the generative system and its relation with the interfaces with the extra-linguistic world. I will discuss five small sets of data which have been identified between mid-1990 and 2015. These sets of data are remarkable because they are built on apparent paradoxes which look like candidates that demand a general answer, and because this answer may have an important implication for the architecture of the language faculty. Of course, this will bring us back to Capriccio.

\footnotetext{
J. Bayer $(\bowtie)$

University of Konstanz, Konstanz, Germany

e-mail: josef.bayer@uni-konstanz.de
} 


\section{German Indefinites and Lexical Case}

German is a Case-marking language in which four Cases can be distinguished: nominative, genitive, dative, and accusative. Due to far-reaching loss of nominal Case-inflection, the language has many nominals that do not show any Case morphology. Indefinites such as was ("what"), etwas ("something"), and nichts ("nothing") are an example, but also feminine substance nouns such as Hitze ("heat"), Kälte (“coldness"), Freude (“joy"), Wut ("rage"). As Gallmann (1996) and Bayer et al. (2001) observe, these nominals can appear in their bare form in contexts in which they are assigned (or check) structural Case (nominative, accusative) but not in contexts in which lexical Case (dative or genitive) is required. ${ }^{1}$

(1) a. Nichts ist schiefgegangen $\quad$ NOM nothing is wrong.gone

'Nothing went wrong'

b. Wir haben nichts erlebt ACC we have nothing experienced

'We haven't experienced anything'

1 (i) Die Feuchtigkeit hat kein-em Haus geschadet the humidity has no-DAT house harmed

(ii) Der Kanzler konnte sich de-r Überweisung erinnern

the chancellor could REF the-GEN transfer remember

are grammatical because the quantifier in (i) bears overt dative Case, and the determiner in (ii) bears overt genitive Case. There is another use of nichts by which (1c) would be ok. This use is irrelevant here. For discussion, see Bayer (2009). Readers familiar with German may wonder why P-governed dative is fine. Consider the preposition mit, which requires dative case on its complement.

(iii) a. Der Chef war mit nichts zufrieden the boss was with nothing content

'The boss wasn't satisfied with anything'

b. Man muss mit Kälte rechnen one must with cold reckon

'One needs to be prepared for cold temperatures'

My answer to this is that $\mathrm{P}$ is not an assigner of dative Case but rather the exponent of dative Case. The true Case-relevant structure is N(P) + P. See Bayer et al. (2001) but in particular Bayer and Bader (2007). 
c. *Die Feuchtigkeit hat nichts geschadet $^{2}$ the humidity has nothing harmed

'The humidity didn't harm anything'

d. *Der Kanzler konnte sich nichts erinnern the chancellor could REFL nothing remember 'The chancellor could not remember anything'

(2) a. Kälte stört mich nicht cold disturbs me not

'Coldness doesn't disturb me'

b. Ich kann Kälte gut ertragen

I can cold well bear

'I can well tolerate coldness'

c. *Du darfst diese Pflanzen nicht Kälte aussetzen you must these plants not cold expose-to

'You must not expose these plants to coldness'

d. *Ich kann mich Kälte lebhaft erinnern

I can REFL cold vividly remember

'I have vivid recollections of coldness'

Insertion of the definite determiner yields the expected semantic effect of a definite reading.

${ }^{2}$ Manfred Bierwisch (p.c.) observes the following datum which could pose a counterexample. e.g.

(i) Der Versuch nützt nichts und niemand-em the attempt serves nothing and nobody-DAT

'The attempts neither serves anything nor anyone'

The verb nützen requires dative Case but only the second nominal, niemandem is overtly Dative-marked. Working with this example reveals interesting aspects. In (ii), we simply permute the two parts of the conjunctive phrase, and the result is ungrammatical:

(ii) *Der Versuch nützt niemandem und nichts.

Similarly, if the conjunction phrase gets disrupted by extraposition, which is otherwise fine:

(iii) Ich glaube, dass der Versuch niemand-em genützt hat (*und nichts)

I believe that the attempt nobody-DAT served has and nothing

(iv) *Ich glaube, dass der Versuch nichts genützt hat und niemand-em

My preliminary conclusion is unattractive but at this moment justified: The coordinated phrase in (i), nichts und niemand-em, is headed by the dative morpheme-em, i.e. [[nichts und niemand]em], absolutely not typical for an inflection system but perhaps nevertheless worth considering. 
(3) a. Die Kälte stört mich nicht NOM

'The (actual atmospheric) cold temperature does not bother me (e.g.

because I' $m$ wearing a warm coat)'

b. Ich kann die Kälte gut ertragen

ACC

'I can easily bear the (actual atmospheric) cold temperature (e.g.

because I'm wearing a warm coat)'

In these examples, the use of the definite determiner has a clear semantic effect. We speak of low temperatures in general or about the specific low temperature of here and now. ${ }^{3}$

Observe now that the deviant cases in $(2 \mathrm{c}, \mathrm{d})$ are rescued when the definite determiner is used because the determiner is overtly Case-marked. Interestingly, the distinctive semantic effect that is observed between the use and nonuse of the definite determiner is absent when we turn to the lexical Cases. ${ }^{4}$ Insertion of the determiner rescues the examples because the determiner bears morphological Case. Simultaneously, the example is ambiguous between the definite and the indefinite/ nonspecific interpretation of die Kälte.

(4) a. Du darfst diese Pflanzen nicht der Kälte aussetzen

(i) 'You must not expose these plants to the (actual atmospheric) cold temperature'

DEFINITE/SPECIFIC

(ii) 'You must never expose these plants to cold temperature'

DEFINITE/NON-SPECIFIC

b. Ich kann mich der Kälte lebhaft erinnern

GEN

(i) 'I have vivid recollections of the cold weather (e.g. when I went skiing last year in Austria)'

DEFINITE/SPECIFIC

(ii) 'I have not forgotten how it feels

when it is very cold'

DEFINITE/NON-SPECIFIC

\footnotetext{
${ }^{3}$ The definite determiner allows also a generic interpretation as in
}

(i) Die Kälte ist das größte Hindernis für den Energietransfer the cold is the biggest handicap for the energy.transfer

Although (i) is hardly distinguishable from a version with the bare noun Kälte, there seems to be a difference. The definite description works here as it does in natural kind readings like in The lion lives in Africa. Also there we find an interpretive closeness with Lions lives in Africa. Once the realm of natural kinds is left, things look differently.

(ii) a. Cuckoo-clocks are made in the Black Forest

b. ??The cuckoo-clock is made in the Black Forest

${ }^{4}$ The example with the genitive yields the same effect but sounds less idiomatic. Speakers would prefer a PP after the verb sich erinnern. One should bear in mind that the verb-governed genitive has a fragile status in contemporary German. 
The interesting fact is that the nonspecific bare NP-meaning is available in spite of the use of the definite determiner, and that this is the only way to express this meaning.

Could this be a funny accident? One can exclude the possibility that in addition to the regular semantically interpretable determiner D-1, there is a meaningless or heavily underdetermined determiner D-2 which occurs precisely for the purpose of Case-marking in the lexical Cases. There are at least two reasons why an account along these lines would fail. The first is that many varieties of German show a pleonastic definite determiner on proper names, especially on persons' names, e.g., der Hans (the John), der Peter (the Peter), die Katharina (the Catherine), and die Maria (the Mary), and that its application is independent of Case. The second and somewhat more intricate reason is that semantic distinctness can be achieved independently of the application of the definite determiner. As soon as lexical Case is spelled out elsewhere, e.g., on a prenominal adjective, interpretive differences were obtained, and the different interpretations map on the presence versus absence of the determiner.

(5) a. In Kalkutta konnte man sich d-er groß-en Kälte nicht erinnern the-GEN big-GEN cold

'In Calcutta, no one could remember the particularly low temperature that held at a particular time in history'

DEFINITE/SPECIFIC

b. In Kalkutta konnte man sich groß-er Kälte nicht erinnern

big- GEN cold

'In Calcutta, one could not remember any particularly low temperature in history'

INDEFINITE/NON-SPECIFIC

In conclusion, one can be quite sure that the definite determiner is semantically interpreted wherever it distinguishes between two (or more) interpretations. ${ }^{5}$ Our interest will be what happens when this is not the case. Before we turn to this, let us take a look at another case in point.

\section{Specificity in Turkish}

The following example shows that a very similar situation holds in Turkish, a language which is unrelated to German. Like many languages that provide examples of Differential Object Marking (DOM), Turkish shows an interpretive effect

\footnotetext{
${ }^{5}$ Application of the definite determiner to proper names is semantically vacuous because proper names are rigid designators (see Kripke 1972) and therefore automatically definite. Thus, the definite determiner is pleonastic, and one can wonder what its motivation is. The usual answer is that it makes Case explicit.
} 
that comes along with Case morphology. According to general wisdom, the morpheme $-(y) I$ in Turkish is not only an accusative Case marker but also a marker of specificity, see Enç $1991 .^{6}$ This is made clear by the fact that it can be applied to indefinites. ${ }^{7}$

(6) a. (Ben) bir kitap oku-du-m.

INDEFINITE/NON-SPECIFIC

I a book read-PAST-1SG

'I read a book'

b. (Ben) bir kitab-1 oku-du-m.

INDEFINITE/SPECIFIC

I a book-ACC read-PAST-1SG

'I read a certain book'

Specificity is rooted in a partitivity relationship. According to von Heusinger and Kornfilt (2005, p. 24,) the referential index of a specific expression must be in an inclusive relationship to the set of corresponding indices of an established set (established in the discourse or made otherwise salient). This could be expected to be the reason for the contrast between (7a) and (7b).

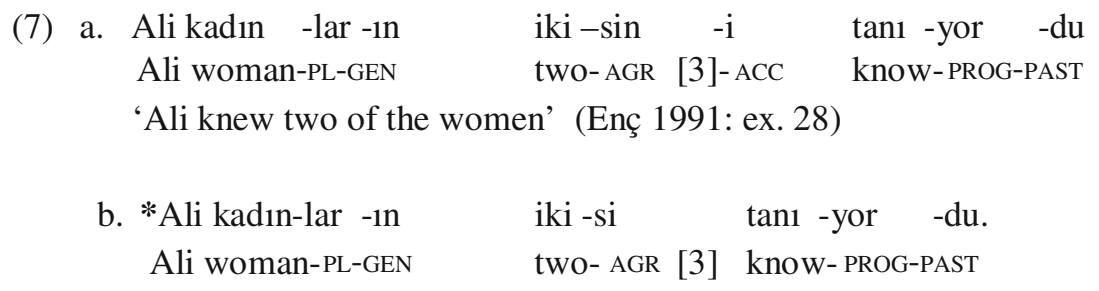

(7b) would be deviant because iki (two) has to be specific by virtue of denoting a subset of an established set. It has first been noticed by Kornfilt (2001) that this argument does not succeed. Kornfilt as well as von Heusinger and Kornfilt point out that there are contexts in which $-(y) I$ is required independently of semantic interpretation. Its absence would yield ungrammaticality. The morpheme $-(s) I(n)$ is a nominal agreement marker which has to be followed by the accusative marker in a transitive context. ${ }^{8}$ Interestingly, this rule holds no matter what, and $-(y) I$ stops

${ }^{6}$ Outside concrete examples, we write $I$ because the segment is subject to vowel harmony.

${ }^{7}$ One could conclude that $-(y) I$ is a definiteness marker like the definite determiner the in English.

(i) (Ben) kitab-1 oku -du $\quad-m$

I book-ACC read-PAST-1SG

'I read the book'

But as other examples show, this cannot be the case.

${ }^{8}$ Von Heusinger and Kornfilt (2005) compare $-(s) I(n)$ with one in English.

(i) I compared various models and bought the new *(one)

The same can be seen in Bangla where the classifier - $T a$ works like a nominal exponent. 
performing its usual job of distinguishing between a +specific and a -specific interpretation. Consider (8).

(8) Kitap-lar-1n iki $\quad$-sin $\quad$-i $\quad$ al,

book- PL-GEN two - AGR (3) - ACC buy

geri $-\sin \quad-i \quad k u t u-d a$ birak.

remainder - AGR (3) - ACC box-LOC leave

'Take (any) two of the books and leave the remainder [of the books] in

the box'

Crucially, the accusative-marked subset of books may be interpreted as nonspecific. This would be unexpected if $-(y) I$ is lexically predetermined as +specific. Von Heusinger and Kornfilt (2005: 37) conclude: Where the accusative marker is required for formal reasons, it is not a reliable marker for specificity; elsewhere, it $i s$. The case is on a par with the German definite determiner. We can follow their generalization and say: Where the definite determiner is required for formal reasons, it is not a reliable marker for definiteness (or maybe specificity); elsewhere, it is. Let us now turn to a third case.

\section{Specificity in Bangla}

The Bangla object Case marker -ke applies to a direct human object (DO); it cannot be applied to nonhumans. ${ }^{9}$

(9) a. ami chele-Ta-ke dekhechi

I boy-CL-Do saw

'I saw the boy'

b. ami dur-Ta $(*-k e)$ dekhechi

I mouse-Cl saw

'I saw the mouse'

An indirect object (IO), on the other hand, must be marked with -ke no matter what its semantic status is.

(10) a. dilip chele-Ta $*(-k e)$ khabar dilo

dilip boy-CL - IO food gave

'Dilip gave food to the boy'

b. dilip ĩdur-Ta *(-ke) khabar dilo

'Dilip gave food to the mouse'

(ii) ami nana rokom rong-er gaRi dekhechi ebong nil *(-Ta) kinechi

I different color-GEN car seen.have and blue CL bought

'I looked at cars of different color and bought the blue one'

${ }^{9}-\mathrm{Ta}$ is the neutral classifier; in the cases considered here, it functions as a definiteness marker. 
That -ke marks specificity can be seen in the following data, provided by Probal Dasgupta (p.c.) in which the numeral quantifier $d u T o$ quantifies over the set denoted by the common noun. ${ }^{10}$ (12) shows that the semantic factor +human is again obsolete.

(11) a. ami du -To chele-ke khũjchilam

INDEFINITE/SPECIFIC

I two-CL boy-DO searched

'I was looking for two boys (known to me)'

b. ami du -To chele khũjchilam

INDEFINITE/NON-SPECIFIC

'I was looking for two boys (e.g. as opposed to two girls)'

(12) a. dilip du-To chagol-ke khũjche

INDEFINITE/SPECIFIC

dilip two- CL goat- DO searches

'Dilip is looking for two goats (e.g. which he had lost before)'

b. dilip du-To chagol khũjche

INDEFINITE/NON-SPECIFIC

'Dilip is looking for two goats (e.g. as opposed to sheep)'

Observe now that this difference in specificity can be suspended. As Probal Dasgupta (p.c.) points out, the -ke marked DP in (13) is ambiguous between the two relevant interpretations.

(13) khali dilip-i du-To chagol*(-ke) du-To bhERa bhab-te pare only dilip- FOC two-CL goat - DO two- CL sheep think- INF can 'Only (stupid) Dilip can mistake two goats for two sheep'

chagol-ke can be interpreted as arbitrary goats or particular goats, known to the speaker. The context is exactly one in which $-k e$ is required for the reason of exceptional case marking. Once again, we see that the semantic interpretation of the object marker stops or remains ambiguous as soon as it is required for a grammar-immanent formal reason.

So far, the examples were related to objects and their interpretation. Before one may develop the idea that something construction-specific is at work here, let us consider two more cases, the first one from Romanian genitive-marking, the other from the verbal syntax of German.

\section{Genitive in Romanian}

Romanian has an enclitic definite determiner, which can be represented by the archimorpheme - L-, as seen in codru-l (forest-D; 'the forest') or frate-le (brother-D; "the brother"). The regular interpretation as a definite determiner is also seen in (14b). $-L$ - is required to assign genitive Case. In (14b) it is inherent in prietna.

\footnotetext{
${ }^{10}$ Notice that $-T o$ is a pure classifier here, without the import of definiteness. I suppose it is, on a par with other forms, a variant of $-\mathrm{Ta}$.
} 
(14) a. Băiatu-l înalt a plecat

boy -L tall has left

'The tall boy has left'

b. Prietna băiatu-lui înalt a plecat

friend(F)-L boy -L(GEN) tall has left

'The tall boy's girlfriend has left' $\quad$ Grosu (1994:160)

As Grosu (1994: 147) points out, $-L-$ "is the sole assigner of GEN(itive) Case in Romanian, and this, regardless of whether or not it has Determiner status." In the following example, which was provided by Alex Grosu (p.c.), one can see that in the genitive construction $-L$ - must appear on the functional preposition $a$, although there is no definite DP in the construction.

(15) Un palat*(a-1) un-ui rege

a palace a-L a-Gen king

'a palace of a king'

Under the natural assumption that the grammar of Romanian employs only one underlying - $L$ - morpheme, this could be another example which is of relevance here. As a determiner, $-L$ - competes with the indefinite $u n$ - and therefore exerts its semantic impact. As a default form, it is the only form available to satisfy the requirement of genitive assignment. It has no competitor, and it is therefore free of any definiteness implications.

\section{Satisfying the V2-Constraint in German}

The examples considered so far have to do with the referentiality of nominal expressions. To see that semantic lacunae of this kind are independent of this domain of grammar, let us consider yet another example from German, but this time one from the grammar of the verb. Certain dialects and/or registers of German have the possibility of using tun ("to do") as the carrier of finiteness morphology. For details see Abraham and Fischer (1998), Eroms (1998) and Schwarz (2004), among others. The data which follows have originally been described in Bayer (2008).

(16) Ich glaube, dass er grade den Müll hinunter tragen tut

I believe that he right.now the garbage down carry does

'I believe that he is right now bringing the garbage down'

(17) Er tut grade den Müll hinunter tragen tut

'He is right now bringing the garbage down' 
This example shows that German is V-final in its base (see (16)), and that the finite verb moves up to the C-position in the root clause (see (17)). German being a "rigid" V2-language, it would normally be the lexical verb that moves. This is shown in (18), where we use strike-out to signal movement.

(18) Er trägt grade den Müll hinunter trägt

he brings just the garbage down

'He is right now bringing the garbage down'

Unlike English do, which has developed a purely auxiliary sidetrack, the German verb tun is up to now a regular open class lexical verb, ${ }^{11}$ which retains its lexical semantics throughout. As a consequence, tun is only compatible with VPs that denote an event which is under the control of an agent. In terms of Aktionsart, this includes states as long as these are under the control of an agent. The VP auf dem Sofa liegen ("to lie on the sofa bed") in (19) is a stage-level predicate (SLP), see Carlson (1980).

(19) Der Hund tut schon wieder auf dem Sofa liegentut the dog does already again on the couch lie

'The dog is once again lying on the couch'

Although "lying on the couch" denotes a state, this state is conceptualized as a bounded event which is under the control of some agent, even if the agent is only a dog. Thus, tun can combine with this VP without provoking a semantic crash.

Quasi-eternal properties, individual-level predicate (ILP), such as own, resemble, and lie on a lake are semantically incompatible with tun. They are nonvolitional and can therefore not be agentive in any sense. They are incompatible with tun.

(20) *Er tut einen guten Charakter besitzen he does a good character own Intended: 'He has a good character'

(21) *Er tut seinem Vater ziemlich ähneln he does his father much resemble Intended: 'He much resembles his father'

(22) *Konstanz tut am Bodensee liegen Konstanz does at.the Bodensee lie Intended: 'Constance lies at the Bodensee (=Lake Constance)'

Throughout, the verb tun originates in clause-final position and moves to the C-position. As such it displays its semantic effects which may be compatible with the predicate as in (16) through (19), or not, as in (20) through (22). Notice now that the semantics of tun can be deactivated, and that this is precisely the case when the

\footnotetext{
${ }^{11}$ Nevertheless, Eroms (1998) points out interesting areas of erosion in Bavarian in which tun can be shown to be on a grammaticalization path along the lines of English $d o$ but only centuries later.
} 
predicate itself or a projection of it has been moved to SpecCP. The following variants of (20) through (22) are spotless. No semantic in congruency obtains.

(23) [Einen guten Charakter besitzen] tut er auf alle Fälle a good character own does he in any case 'A good character he has for sure'

(24) [Seinem Vater ähneln] tut nur ER his father resemble does only he

'Resemble his father only HE does'

(25) [Am Bodensee liegen] tut Stuttgart zum Glück nicht at.the Lake.Constance lie does Stuttgart luckily not 'Luckily, Stuttgart does not lie at Lake Constance'

In these cases, the finite form of tun cannot have been merged like any other lexical verb in VP. It must have been base-generated in C. If it had been merged in clause-final position, it would have left a V-copy, and this copy would give rise to the semantic clash described above. Obviously, tun is the "default" form that is selected as the carrier of the relevant features (phi-features and T) of the finite verb. ${ }^{12}$ The interesting aspect of this is in the present argumentation that the semantics of tun is switched off precisely when no alternative exists to rescue the derivation of the sentence. The finite form of tun "rescues" the V2-construction. Its insertion is an act of repair. This puts the present case on a par with the four previous cases. It goes without saying that postulation of a second meaningless tun (tun-2) next to the regular tun (tun-1) would be nothing but a restatement of the facts. ${ }^{13}$

\footnotetext{
${ }^{12}$ Yiddish and various German dialects show that another choice is a finite copy of the topicalized nonfinite lexical verb. See Cable (2004), Fleischer (2008), Källgren and Prince (1989).

${ }^{13}$ Yvonne Viesel (p.c.) informs me that there are speakers for who the semantic restriction described above does not hold.

(i) Eine Geschichte, die meiner einigermaßen ähneln tut, möchte ich euch heute mitteilen! a story which mine somewhat resemble does want I you today tell 'Let me tell you today a story which resembles my own story to some degree' https://www.seniorbook.de/themen/kategorie/fitness-und-gesundheit/artikel/33847/momentezurueck-holen
}

Similar ignorance of the semantic restriction can be observed in poetry as in a German folk song where it is important that -hut rhymes with tut.

(ii) Schön ist ein Zylinderhut, wenn man ihn besitzen tut nice is a cylinder.hat if one it own does 'A top hat is nice if one owns it'

The core of my argument is not affected by such examples because ALL speakers, including those for who (i) and (ii) are semantically deviant or at best options in poetry, accept examples of the type in (23) through (25); the latter are, in fact, the only choice which the syntax of Standard German offers. 


\section{A Generalization}

The five cases in point signal that there is a common denominator. What is it? My suggestion is the following. There are formal constraints that supervise the grammar's computational steps. These may be universal constraints as they have been studied extensively in generative grammar but may be also language specific ones. Assume these constraints are rigid and must be observed no matter what. How are these constraints satisfied? Normally, there is a multitude of lexical options. In English, the constraint on determining a singular NP can be satisfied by a choice between different determiners (the, a), a quantifier (some, every), a wh-determiner (which), a negative quantifier (no), a possessive ( $m y$, her) etc., and combinations of these (whose) etc. The residual V2-constraint as it shows up in subject-aux-inversion can be satisfied by a choice between $d o$ and a number of auxiliary or modal verbs. All these lexical choices yield distinctive semantic results. Or consider the Case Filter. The set of case-bearing nominals that can satisfy the Case Filter is huge, and the fact that each nominal may be associated with different semantic features and compositions thereof gives rise to an explosion of distinctive meanings. Occasionally, however, there may not be any alternative. In this case, only a single form can be chosen to satisfy the constraint. An example may be expletives. English uses the semantically eroded locative adverb there. Selection of the lexical alternative here would kill the expletive construction. German uses es (it) as in Es herrschte einst ein Tyrann auf dieser Insel (it ruled once a tyrant on this island). Selection of an alternative would either kill the construction or change the meaning. Another well-known case is $d o$-support in English. The lexical item $d o$ is a default which as such lacks alternatives. Its selection does not induce a lexical semantic effect. Imagine a situation in which there is only one way to satisfy a constraint. No alternatives. Assuming semantic features for the sake of the argument, can there be meaning without there being alternatives? To draw a comparison with phonology, can there be a phonemic value without there being opposition? If a language employs a vocalic system which lacks front rounded vowels, it is futile to ask for the difference between/y/and/œ/, which in German distinguishes Düsen (nozzle-PL) from dösen (to doze, to daydream) or Tüten (bag-PL) from töten (to kill). A language may well have access to a sound like [y], but in the absence of any formal opposition to other candidates like $[\mathrm{u}]$ and $[œ]$ and $[\mathrm{e}]$, it would not be able to make any symbolic use of it. Extending this old structuralist insight to semantics, one can argue that forms without alternatives lack semantic features and interpretation altogether. ${ }^{14}$ The common denominator of the default form considered so far seems to be exactly that they lack semantic alternatives and as a consequence lack meaning altogether. It is, of course, not

\footnotetext{
${ }^{14}$ For example, to grasp the meaning of here, one has to grasp the meaning of there and what distinguishes the two. Or, to change the example, to compute the meaning of She is not here one presumably needs access to the meaning of She is here. Work on the processing of negation suggests indeed that negation is initially represented as affirmation and persists as affirmation in memory. See Hasson and Glucksberg 2006. For discussion of the structural notion of semantic space in de Saussure's and in Jakobson's work, see Caton (1987).
} 
easy to determine more precisely what a default form is, and why a form develops this privilege over others. But even with an intuitive understanding of markedness, it should be clear enough what is at issue. This enables us to formulate the following principles.

(26) Constraint satisfaction

Satisfy morphosyntactic constraints rigorously!

(27) Semantic effect of Merge

Merger of a lexical item LI has an effect on the interface with semantics iff LI is chosen from a set of alternatives $\left\{\mathrm{LI}_{1}, \mathrm{LI}_{2}, \ldots, \mathrm{LI}_{\mathrm{n}}\right\}$.

(28) Default

Due to a markedness convention M, a lexical item LI may be disconnected from its set of alternatives $\left\{\mathrm{LI}_{1}, \mathrm{LI}_{2}, \ldots, \mathrm{LI}_{\mathrm{n}}\right\}$.

About (26), one can be sure that it is a simplification; let us call it an "idealization." It ignores constraint ranking as in OT or other forms of gradedness. For the present discussion, however, caveats in this direction appear to be less relevant. The background assumption of (27) is that merger of an LI imports, among other properties, semantic features by virtue of semantic alternatives. The background assumption of (28) is that selection of the least marked LI of a set can suspend the competition and therefore semantically isolate the LI.

With this equipment, let us now return to the paradigmatic examples we have introduced in the previous sections. All the forms under consideration are LIs which have alternatives. The German definite article has competitors, the Turkish accusative Case marker has at least the zero form as a competitor, and the German verb tun has thousands of verbs as competitors. So to make the argument work, it must be assumed that the constraint satisfiers in question are something like prototypes, and that they have reached their privileged state thanks to this quality. ${ }^{15}$ The reasons for this may be manifold, but unmarked status and frequency are plausible conditions. For the actual argumentation, it is important to keep in mind that all these LIs are completely normal words or morphemes in the respective languages but have the potential for default status. Once they kick into the system as defaults, they are outside the system of opposites. Once they are defaults, they are constraint satisfiers with no semantic competitors and, according to our reasoning, semantic impact.

\footnotetext{
${ }^{15}$ Notice that in the traditional grammar of German the verb is called "tun-Wort." Ascribing similar prototype status to the definite determiners der, die das as well as to the Turkish accusative morpheme - $(y) I$ does not seem to be completely far-fetched.
} 
Consider first the definite article in German. Application of the indefinite determiner ein is not admissible in nouns such as Kälte, Hitze, and Freude. ${ }^{16}$ The relevant constraint is the Case Filter by which no case-less (lexical) NP/DP can survive. According to Bayer, Bader, and Meng (2001), while structural Case is provided (or rather valued) by the functional syntactic heads $v$ and $\mathrm{T}$, lexical Case has to be imported morphologically or otherwise, for instance by a "functional" preposition. The definite determiner can do the job of providing overt morphology as in $d$-er Kälte (the-DAT cold). It is natural to assume that it is the only choice. Other choices like, for instance, stark-er Kälte (strong-Dat cold) would solve the overtness problem but import additional semantic material which may be unwanted or may not be in the numeration that is used for the composition of a structure. If, due to the definite determiner's lack of alternatives, its form is incapable of contributing semantic features, the grammar has the freedom of interpreting the lexically Case-marked DP, e.g., der Kälte, unrestrictedly, namely as either definite or as indefinite/ \pm specific. This is exactly what we observe.

The Turkish example with the accusative marker $-(y) I$ works accordingly. Normally, there is the choice between $-(y) I$ and zero. Application of $-(y) I$ yields the semantics of specificity; nonapplication of $-(y) I$ yields the nonspecific reading. According to Kornfilt, (2001) and von Heusinger and Kornfilt (2005), however, the nominal agreement marker $-(s) I(n)$ leaves no choice. The accusative Case marker must follow $-(s) I(n)$, or the derivation perishes. In this case, $-(y) I$ is the default option, and consequentially, its usual semantic impact is lacking. It is then up to extra-syntactic forces to give the NP a specific or a nonspecific interpretation.

The Bangla example with the object marker -ke works accordingly. The specificity effects which are induced by the Case-particle - $k e$ are suspended as soon as a formal Case requirement - here ECM — demands marking of overt and distinctive Case. Normally, the choice between - $k e$ and zero is an alternative, and the semantics respond to this by assigning specificity to - $k e$ while leaving zero for the non-specific interpretation. Under the ECM condition, the rules of the game have changed. Overt case-marking seems to be the stronger requirement. Thus, once the available case-marker $-k e$ is selected to do the job of constraint satisfaction, the usual semantic import of $-k e$ is suspended.

The Romanian example shows that what is generally the morpheme responsible for a definite description of a DP appears as the sole assigner of genitive Case, and if it appears in this function, its semantic impact as a definiteness marker ceases to exist. Again, there is an alternative in the grammar of Romanian between using - $L$ or $u n$. No alternative to $-L$ - is around for establishing genitive assignment. The remarkable property is that in this case $-L$ - lacks its usual semantic impact.

Coming finally to the satisfaction of the V2-constraint in German, the choice is normally between quasi all the verbs of the language, including the verb tun, which, if selected, introduces its agentive semantics. Consider now the special case in

\footnotetext{
${ }^{16}$ To be sure, I am working here with a simplification that leaves aside special constructions as well as certain dialectal variants.
} 
which, due to $\mathrm{V}(\mathrm{P})$-tropicalization, no finite verb is left over that could be moved up to $\mathrm{C}$ for satisfaction of the V2-constraint. In this case, tun is chosen as the default form. ${ }^{17}$ Being the default form, it has no alternative. According to our reasoning, this is the cause for its not having any meaning. The verb is, so to say, nothing but the morphological carrier of the relevant features $(\varphi$ and $T)$. Notice that in this situation German tun is the same as English $d o$. It works on a purely formal basis, with no consideration of semantics. This explains the absence of a semantic clash between the verb tun and the semantics of the VP. ${ }^{18}$

\section{The Consequence}

Coming back to the question in the title of this article, Prima la musica, dopo le parole?, let me take musica to refer to a purely formal system without any component of intensional meaning and ergo without the capacity of mapping onto Fregean reference (in German "Bedeutung"). Let me take le parole in a very broad sense as descriptions of meaning. We could then venture an affirmative answer to this question. Syntax (including morphology) seems to be a closed system, characterizable as I(internal)-language by Chomsky (1986). It runs on the basis of formal operations characterized in the Minimalist Program as potentially recursively applying merge and agree operations, and it does so mandatorily and without the influence of external factors of purpose, communication, style, etc. However, unlike the systems of music, which is arguably semantics-free, natural language syntax employs symbols that are most of the time open to semantic interpretation. The semantic system needs and loves alternatives. It looks as if the whole space of alternatives is exploited by semantic interpretation. Non-use would be luxury and is

\footnotetext{
${ }^{17}$ It is unclear to me why it is tun (to do). According to my reasoning, it could as well be the equally general verb machen (to make).

${ }^{18} \mathrm{We}$ assumed so far that in this case a finite form tun is base generated in C. There can be no copy in clause-final position because such a copy would declare tun to be a lexical part which composes with some VP and yields a complex VP, namely [tun $[\mathrm{VP} . .$.$] tun], give rise to regular semantic$ composition and therefore activate the semantics of tun. Notice as a potential problem, however, that tun agrees in $\varphi$-features with the subject of the clause.

(i) [Den Müll hinunter tragen] tu-t er nie the garbage down carry do-3SGhe-3SG never 'Bringing the garbage down, he never does'

(ii) [Den Müll hinunter tragen] tu-st du nie the garbage down carry do-2SG you-2SG never 'Bring the garbage down, you never do'

The problem is that base-generation of finite tun in $\mathrm{C}$ would fail to explain how agreement works. Masayuki Oishi (p.c.) suggests that tun is base-generated in T, where it agrees with the clausal subject, and then moves to $\mathrm{C}$ for satisfaction of the V2-constraint. Since in this case, there is no copy in the VP, and the semantic problem still does not arise. I adopt Oishi's solution.
} 
therefore avoided. ${ }^{19}$ There can be no doubts that this is one of the primary sources of linguistic creativity. If we are right, there are however symbols which can be recruited as constraint satisfiers while lacking the property of having alternatives. These are our default candidates. Their role and appearance in musica/syntax/ I-language is unspectacular. They do whatever grammar dictates them to do. On the way to the semantics interface, however, these elements are identified as not allowing alternatives. As a consequence, the interpretive system circumvents them. One way of circumvention that we have detected is that the constraint satisfier is simply skipped by the semantics. ${ }^{20}$ This is clearly the case when tun is inserted for no other reason than the satisfaction of the V2-constraint. The other but clearly related way of circumvention that we have detected is to ignore the constraint satisfier by leaving its interpretation open to the semantic system. This is the case if we understand the German and the Turkish cases of indefinite/nonspecific interpretation of formally definite/specific markers as under specification, or more precisely suspended specification.

In Strauss' ingenious opera, the question Prima la musical, dopo le parole? remains unanswered because the capricious countess cannot decide who she loves more, the musician or the poet. We may be in a slightly better position than the countess if we can rely on findings like those that have been reported above. These findings speak in favor of the primacy of an encapsulated formal system which is, in a logically independent step, used for semantic interpretation but cannot be identified with it. Semantic interpretation depends on the formal system. An architecture of the language faculty that turns this set-up around would have to show how syntax follows from semantics and ultimately from E-language. ${ }^{21}$ As everybody knows, there is a rich functionalist tradition that tried to follow this idea in one form or the other.

An interesting debate about this issue has been opened by Hinzen (2006) and Leiss (2009). Leiss offers a broad critique of the philosophy of language which, according to her, in its history since the medieval tradition but especially at the time of the so-called linguistic turn tried to devaluate language in favor of various language-external extensional, intensional, or pragmatic foundations. In the so-called nominalist conception, according to Hinzen (2012) and Leiss (2009), language is independent of thought; it "is conceived as merely a system of labels, and thought is

\footnotetext{
${ }^{19}$ One classic observation is that natural languages have more or less no synonyms. Even if German nouns such as Gesicht, Antlitz, Visage, and Fresse refer to "face," and differences may at times be hard to be pinned down extensionally, they are semantically very different and can normally not be exchanged. Even in notorious cases like firefly versus lightning bug, there is a difference, albeit only a dialectal/geographical one, see http://www.oldsouthhigh.com/2013/06/10/ lightning-bug-or-firefly/.

${ }^{20}$ Following more closely the syntactic façon de parler, we may speak of "deletion" before transfer to the $\mathrm{C} / \mathrm{I}$-interface.

${ }^{21}$ An extreme position of this belief can be found in Schneider Schneider (1975), where it is not only claimed that semantics must be the foundation of syntax but that the ultimate foundation of both of them must be pragmatics.
} 
structured primarily by logic and has a semantics fixed by relations between concepts and the world unmediated by grammar" (Hinzen 2012:636). This is the reason why logic became the prime formal meta-theory for philosophy. However, as Hinzen argues, there cannot be any language of thought (LoT) as proposed by Fodor (1975; 2008) which is epistemologically prior and therefore independent of grammar-based language, and there cannot be any language-independent logical foundation of cognition. Starting out from the pre-Cartesian "modist" tradition of grammar, Hinzen refers to the Sanskrit grammarian Bharțhari for the idea that an essential property of thought is to be grammaticalized, and that it is the novel linguistic form which generates a novel thought, and not the other way round. Conceptualization and rational thoughts are the results of the specific form that grammar offers.

Above I referred to Chomsky's concept of an I-language. Within the minimalist program, the notion of I-language has acquired a highly restrictive interpretation. Much of what was in the core of syntax in the Principles and Parameters Theory of Chomsky (1981) is now considered to be a matter of "externalization." I-language as a LoT, albeit distinct from a Fodorian one, is characterized by the recursive operations of merge and move while parameterization and other forms of variation are a matter of externalization and are excluded from core syntax. As Berwick and Chomsky (2016: 70) put it, provided with conceptual atoms of the lexicon, the operation Merge, iterated without bound, yields an infinity of digital, hierarchically structured expressions. "If these expressions can be systematically interpreted at the interface with the conceptual system, this provides an internal "language of thought"." According to Noam Chomsky (p.c.) the atoms are radically different in character from any known animal system, and their evolutionary origin remains a mystery. Chomsky suggests that some of them may have been there before LoT was externalized - and in fact, before it could even be internalized, modeled after actor-action schemata and other cognitive structures. It is assumed that the lexicon of atoms for generating LoT includes functional as well as substantive categories, externalized at some stage of the history of homo sapiens. So LoT appears to be pretty much like any natural language, albeit without the ingredients that are now ascribed to externalization. It is not always clear what exactly belongs to externalization, but as Berwick and Chomsky (2016: 11) point out, "externalization includes much more than just vocal/motoric learning and production, encompassing at least aspects of language such as word formation (morphology) and its relationship to language's sound systems (phonology and phonetics), readjustment in output to ease memory load during production, and prosody". Almost certainly, Case would be another aspect of language that is assigned to externalization. The danger I see here is that even the Chomskyan version of LoT could boil down to a semantic language with cognitive priority over the form that language and languages take. How would mismatches between meaning and form arise in the first place? What we found in the present study is evidence for a priority of form that offers itself to conceptual semantic interpretation. Of course, the core grammar's operations of merge and move are first of all formal operations, but there is a lot more in language than merge and move that determines interpretable structure. Case is one such factor, as our consideration of German datives in section "German Indefinites and Lexical Case" has shown. If form, including Case, takes priority over 
semantic interpretation, the form-meaning mismatch and the corresponding semantic lacunae find a systematic answer. But then, of course, Case is more central to core grammar than suggested in the maximally restrictive conceptualization of I-language.

Of course, the few cases considered in the present study allow only preliminary and somewhat speculative conclusions, and they can certainly address the philosophical debate only indirectly. Nevertheless, the "exceptions" we have encountered would be hard to explain in a model which is based on a concept of grammar as a coding device, a tool to encode some grammar-independently formed message. In such a model, why would grammar entertain the bizarre luxury of leaving small lacunae of interpretive indeterminacy or even interpretive irrelevance in its system? Any system built on intentionality and human rationality would discard a system like this. Speculative as the present conclusion may be, the case studies presented here suggest something different, namely primacy of a pure form of constraint satisfaction. By (26), the grammar is completely uniform. In those cases in which constraint satisfaction can be performed by selection of semantic alternatives from the lexicon, the semantic system takes its chance. In the face of a lack of alternatives, the semantics skips over or leaves interpretation to other extra-syntactic factors. If my interpretation of the facts is on the right track, the question in the title of this chapter may indeed have to be answered affirmatively: Prima la musica, -e dopo le parole.

Acknowledgements For discussion and help with data, many thanks to Manfred Bierwisch, Probal Dasgupta, Alex Grosu, Jaklin Kornfilt, Masayuki Oishi, Yvonne Viesel, and Andreas Trotzke. I am particularly indebted to Noam Chomsky for discussing with me some of my questions about his understanding of core syntax and externalization. Any misconceptions and errors are on my side. My research was supported by grant BA $1178 / 9-1$ of the DFG (German Research Foundation).

\section{References}

Abraham, Werner and Annette Fischer. 1998. Das grammatische Optimalisierungsszenario von tun als Hilfsverb. In Deutsche Grammatik - Thema in Variationen. Festschrift für Hans-Werner Eroms zum 60. Geburtstag, ed. Karin Donhauser, and L.M. Eichinger, 35-47. Heidelberg: Winter.

Bayer, Josef. 2009. Nominal negative quantifiers as adjuncts. The Journal of Comparative Germanic Linguistics 12: 5-30.

Bayer, Josef. 2008. What is verb-second? Unpublished manuscript. University of Konstanz. http:// ling.uni-konstanz.de/pages/home/bayer/pdf/Verb-Second.pdf.

Bayer, Josef and Markus Bader. 2007. On the syntax of prepositional phrases. In Interface and Interface Conditions, ed. by Andreas Späth, 157-180. Berlin: de Gruyter.

Bayer, Josef, Markus Bader and Michael Meng. 2001. Morphological underspecification meets oblique case: Syntactic and processing effects in German. Lingua 111: 465-514.

Berwick, Robert C. and Noam Chomsky. 2016. Why Only Us. Language and Evolution. Cambridge, Massachusetts: MIT Press.

Cable, S. 2004. Predicate Clefts and Base-Generation: Evidence from Yiddish and Brazilian Portuguese. Unpublished manuscript. MIT. http://people.umass.edu/scable/papers/YiddishPredicate-Clefts.pdf.

Carlson, Gregory N. 1980. Reference to Kinds in English. New York: Garland Publishing. 
Caton, Steven C. 1987. Contributions of Roman Jakobson. Annual Review of Anthropology 16: $223-260$.

Chomsky, Noam A. 1995. The Minimalist Program. Cambridge, Massachusetts: MIT Press.

Chomsky, Noam A. 1986. Knowledge of Language. New York: Praeger.

Chomsky, Noam A. 1981. Lectures on Government and Binding. Dordrecht: Foris.

Enç, Mürvet. 1991. The semantics of specificity. Linguistic Inquiry 22: 1-25.

Eroms, Hans Werner. 1998. Periphrastic, tun' in present-day Bavarian and other German dialects. In DO in English, Dutch and German, ed. I. Tieken-Boon van Ostade et al., 139-158. Münster.

Fleischer, Jürg. 2008. Zur topikalisierenden Infinitivverdoppelung in deutschen Dialekten: Trinken trinkt er nich, aber rauchen raucht er (mit einem Exkurs zum Jiddischen). Dialektgeographie der Zukunft: Akten des 2. Kongresses der Internationalen Gesellschaft für Dialektologie des Deutschen (IGDD) am Institut für Germanistik der Universität Wien, 20. bis 23. September 2006 (Zeitschrift für Dialektologie und Linguistik Beihefte 135) ed. Peter Ernst and Franz Patocka, 243-268. Stuttgart: Steiner.

Fodor, Jerry A. 2008. LOT 2: The Language of Thought Revisited. Oxford: Oxford University Press. Fodor, Jerry A. 1975. The Language of Thought. Cambridge, Massachusetts: Harvard University Press. Gallmann Peter. 1996. Die Steuerung der Flexion in der DP. Linguistische Berichte 164: 283-314. Grosu, Alexander. 1994. Three Studies in Locality and Case. London: Routledge.

Hasson, Uri and Sam Glucksberg. 2006. Does understanding negation entail affirmation? An examination of negated metaphors. Journal of Pragmatics 38: 1015-1032.

Von Heusinger, Klaus and Jaklin Kornfilt. 2005. The case of the direct object in Turkish: Semantics, syntax and morphology. Turkic Languages 9:3-44.

Hinzen, Wolfram. 2012. The philosophical significance of universal grammar. Language Sciences 34: 653-649.

Hinzen, Wolfram. 2006. Mind Design and Minimal Syntax. Oxford: Oxford University Press.

Källgren, Gunnel, and Ellen Prince. 1989. Swedish VP-topicalisation and Yiddish verb-topicalisation. Nordic Journal of Linguistics 12: 47-58.

Kornfilt, Jaklin 2001. Non-specific partitives and the unreliability of specificity markings. Unpublished manuscript. New York: Syracuse University.

Kripke, Saul. 1972. Naming and Necessity. In Semantics of Natural Language ed. Gilbert Harman, and Donald Davidson. Dordrecht and Boston: Reidel.

Leiss, Elisabeth. 2009. Sprachphilosophie. Berlin: de Gruyter.

Schneider, Hans Julius. 1975. Pragmatik als Basis von Semantik und Syntax. Frankfurt: Suhrkamp.

Schwarz, Christian. 2004. Die tun-Periphrase im Deutschen. Master thesis: Universität München. 